\title{
Poorly differentiated squamous carcinoma of the bronchus: a light and electron microscopic study
}

\author{
A CARLILE, C EDWARDS
}

From the Department of Histopathology, East Birmingham Hospital, Birmingham

SUMMARY As there is little published information on the ultrastructure of poorly differentiated squamous carcinoma of the bronchus 18 examples of this tumour were studied. On light microscopy 10 of the tumours contained foci of keratinisation or intercellular bridges and therefore fulfilled the World Health Organisation's diagnostic criteria. In eight these features were absent, but the overall appearance was sufficiently squamoid to preclude their placement in any other category. On electron microscopy many cells showed the characteristic desmosomes and tonofilaments of squamous carcinoma, but there were also areas of adenodifferentiation. The ultrastructure of both light microscopic groups was identical.

In conclusion, this type of tumour is dimorphic with characteristics of adenocarcinoma and squamous carcinoma on electron microscopy. Keratinisation and bridges are not essential diagnostic criteria: the overall pattern and cellular morphology are more important.

Although poorly differentiated squamous carcinoma of the bronchus is common, there is little information available on its ultrastructure. There have been many published reports on the morphology of bronchial and pulmonary tumours, ${ }^{1-8}$ but few have dealt specifically with squamous carcinoma. ${ }^{9-11}$ In most instances this tumour has been mentioned only in passing, and emphasis has been on the well differentiated variant.

According to the World Health Organisation, ${ }^{12}$ keratinisation and intercellular bridges are essential diagnostic criteria for squamous carcinoma. In our experience, however, many poorly differentiated tumours showing neither of these features are nevertheless "squamoid" in appearance. Such tumours are often classified as large cell carcinoma, a category that has been described as a "wastebasket". ${ }^{11}$

In this study we investigated the results of light and electron microscopy of 10 poorly differentiated squamous carcinomas, diagnosed using the WHO criteria, and eight tumours that were similar in appearance but lacked bridges and keratin. The ultrastructure of the two groups was identical.

\section{Material and methods}

Samples were obtained from 18 patients undergoing pneumonectomy or lobectomy for bronchial car-

Accepted for publication 14 November 1985 cinoma. Blocks of tumour tissue were taken for electron microscopy at the time of operation, fixed in buffered glutaraldehyde, then fixed in osmic acid, and embedded in TAAB resin (TAAB Laboratories, Reading, England). Ultrathin sections were stained with urayl acetate and lead citrate.

After fixation with formaldehyde two to four blocks of tissue were taken from the main tumour mass for examination by light microscopy. Sections were stained with haematoxylin and eosin, mucicarmine, periodic acid-Schiff (PAS) with and without diastase, and alcian blue.

Ten tumours conformed with the WHO definition of poorly differentiated squamous carcinoma on light microscopy-namely, "A tumour fulfilling the criteria for squamous cell carcinoma-that is, keratin and/or bridges, in which, in part, these features are present but the bulk is undifferentiated, or a tumour in which these criteria are discerned with difficulty". ${ }^{12}$ In eight cases neither keratin or bridges were present, but the appearances were sufficiently squamoid to preclude any other diagnosis.

\section{Results}

LIGHT MICROSCOPY

The basic pattern of all 18 tumours consisted of sheets, trabecula, and ribbons of elongated or round cells with poorly defined cytoplasmic outlines. Often there was a pseud inar arrangement, with spaces 


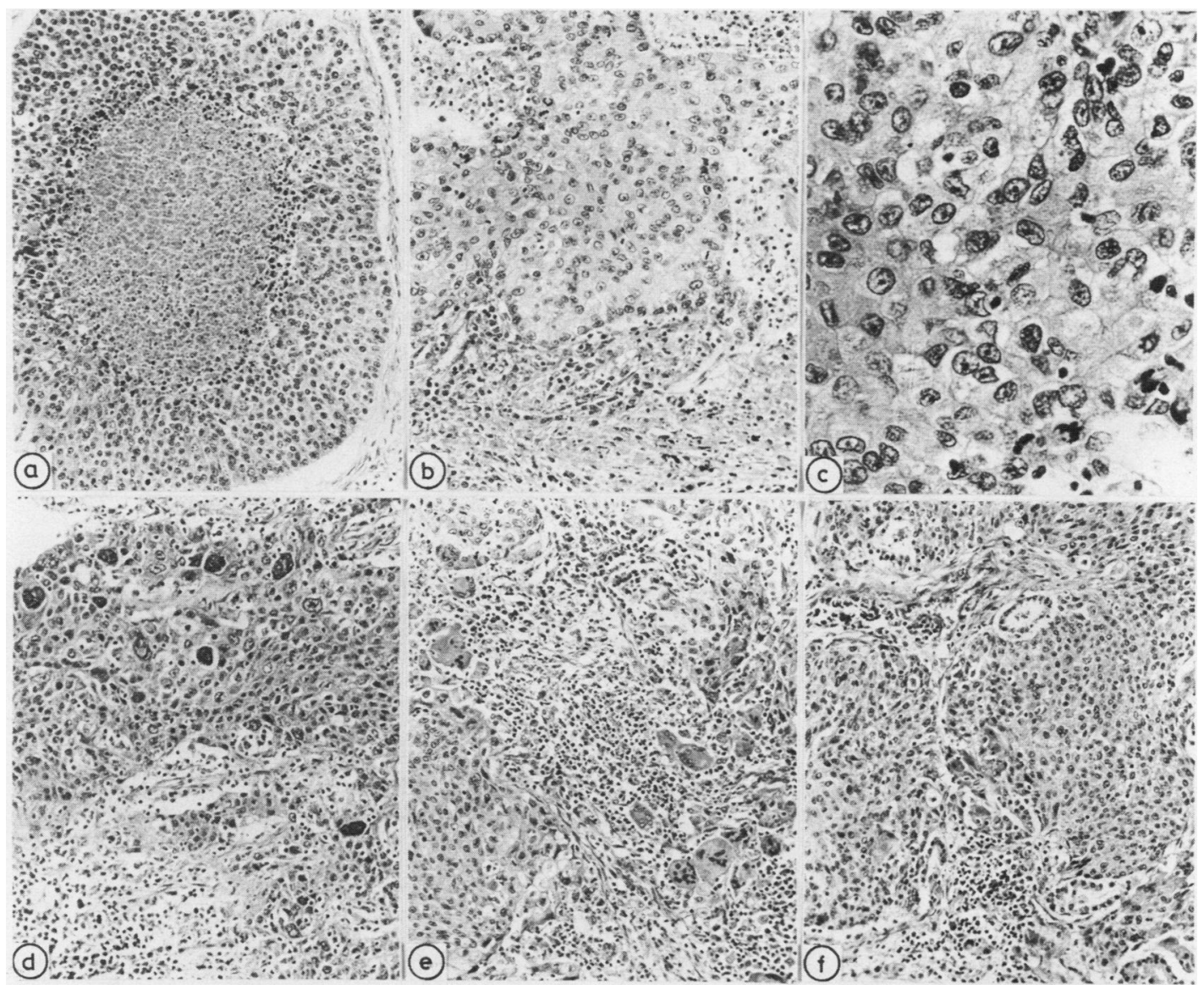

Fig. 1 Light microscopy. (a) Pseudoacinus containing cell debris. $\times 115$. (b) and (c) Poorly differentiated tumour with no keratinisation or intercellular bridges. $\times 115$ and 290 , respectively. $(d),(e)$, and $(f)$. Tumour giant cells, stromal foreign body giant cells, and acinar inclusions, respectively. $\times 100$. Haematoxylin and eosin.

containing necrotic material or nuclear and cytoplasmic debris, surrounded by a layer of neoplastic elements up to 15 cells thick (Fig. 1a). The characteristic stratification of well differentiated squamous carcinoma was generally absent. Nuclei were round or oval, up to $12 \mu \mathrm{m}$ in diameter, with a stippled chromatin pattern or spindle shaped and heavily basophilic. Individual cells in the 10 tumours that met the WHO criteria were keratinised, but there were no epithelial pearls, and bridges were sparse. In two cases the tumour had a distinctly papillary appearance where it grew into the bronchial lumen.

The better differentiated areas often merged with sheets, ribbons, and small clusters of anaplastic elements with larger, more open nuclei up to $18 \mu \mathrm{m}$ in diameter and a single nucleolus (Figs. $1 b$ and $c$ ). In two tumours there were many giant forms with a single, irregular basophilic nucleus up to $30 \mu \mathrm{m}$ in diameter (Fig. 1d), and in one there was prominent "clear cell" change. The stroma varied from tumour to tumour and field to field: sometimes it was delicate and contained thin walled blood vessels or it was collagenous, dense, and hypocellular. In three tumours there was a heavy stromal infiltrate of lymphocytes and plasma cells, and in two there were prominent foreign body giant cells, some of which contained ingested nuclear material (Fig. le).

There was no adenocarcinomatous differentiation in any of the tumours, but in all but three there were occasional cells that gave positive reactions with PAS, alcian blue, and mucicarmine. In most there were small acini up to $45 \mu \mathrm{m}$ in diameter, lined with cuboidal cells and often containing eosinophilic accelular material (Fig. 1f). These structures were particularly common at the edges of the tumours and seemed to be derived from included alveoli. 


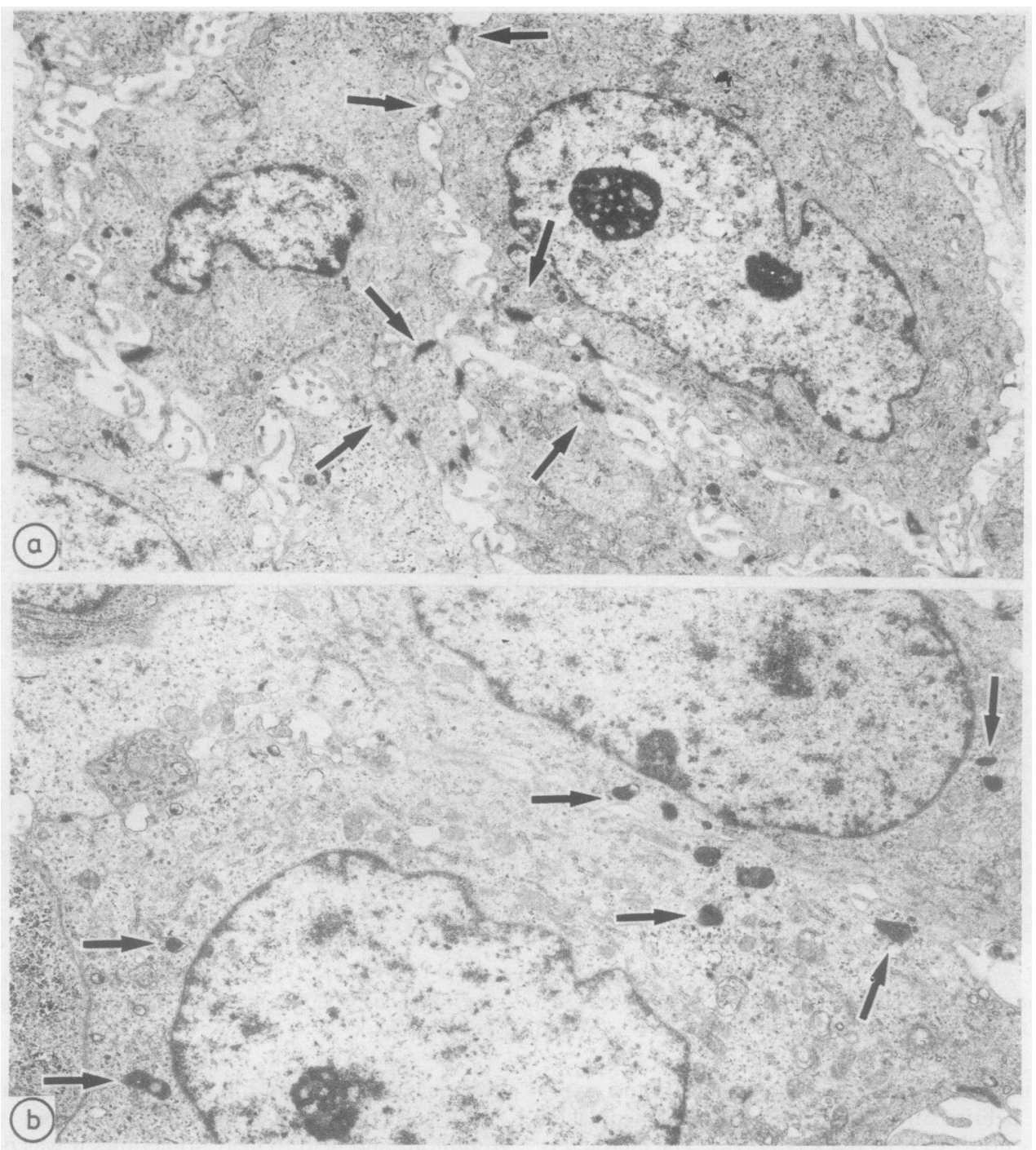

Fig. 2 Tumour cells. (a) Pseudopodal processes and well formed desmosomes (arrows). Between processes, intercellular gap contains irregular microvilli. $\times 6900$. (b) Poorly differentiated tumour cells with smooth cytoplasmic membranes. Occasional dense bodies are present in cytoplasm (arrows) $\times 8600$.

\section{ELECTRON MICROSCOPY}

All the tumours shared a common basic ultrastructure, but as the morphology of individual cells varied widely this became apparent only after several blocks from each tumour had been examined. At low magnifications the tumour cells were elongated, irregular, or polygonal (Figs. 2a and b). Sometimes they were separated by a gap bridged by irregular pseudopodal processes bearing well formed desmosomes with irregular microvilli in between (Figs. 2a and 3a). Elsewhere, adjacent cytoplasmic membranes were smooth and closely applied to each other, forming a straight or wavy double line, often, but not invari- $\mathrm{W}$ ably, joined by desmosomes (Figs. $3 b$ and c). These closely applied cytoplasmic membranes often sepa- 0 rated to form intercellular lumens lined by small cytoplasmic projections or stunted microvilli (Fig. 3d). The intercellular lumens were sealed by poorly formed junctional complexes. The luminal surfaces of cells lining large pseudoacinar spaces were covered by stunted, irregular microvilli; apposing cell membranes were closely applied and bore indistinct junctional 


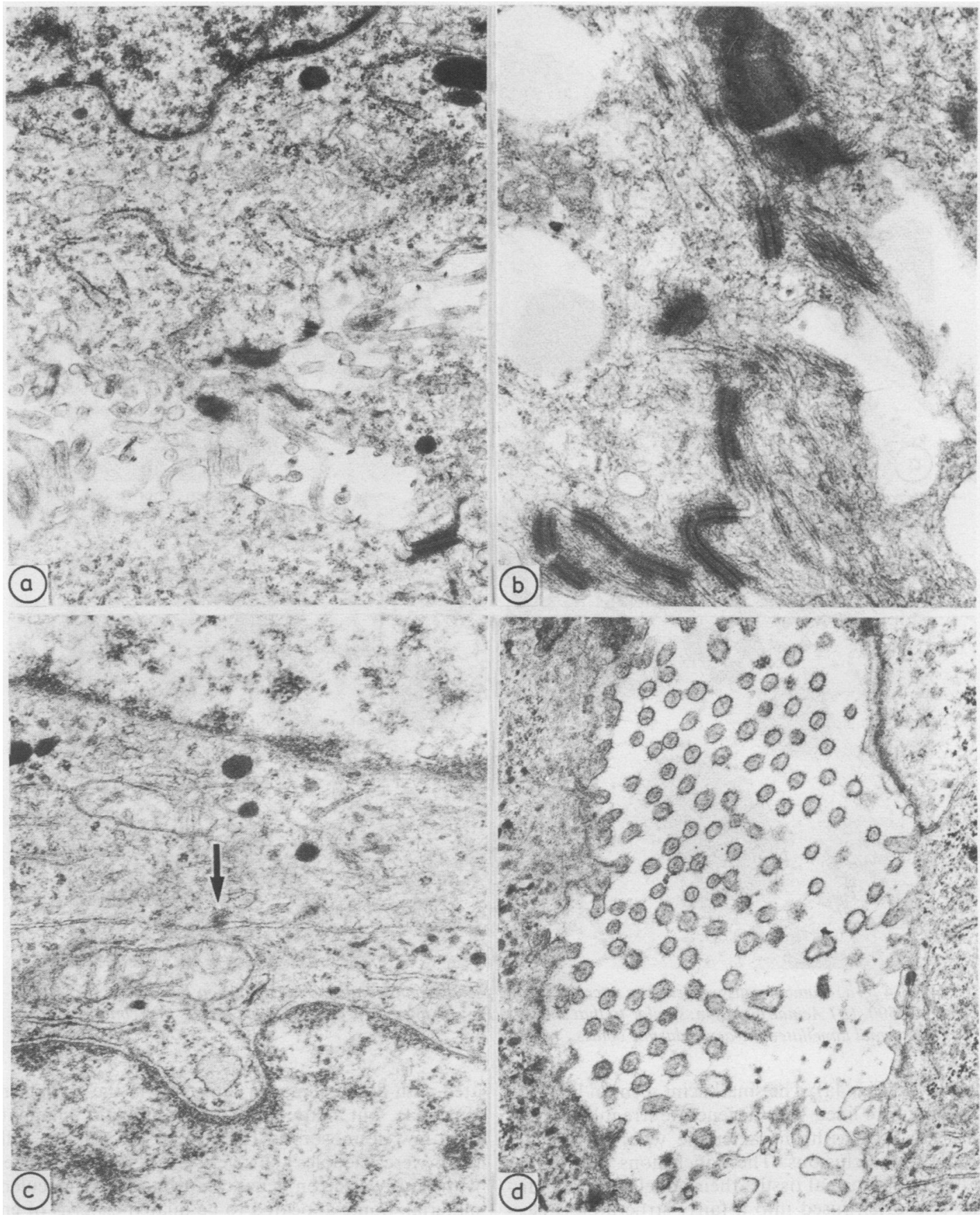

Fig. 3 Cytoplasmic membranes. (a) Pseudopodal processes united by desmosomes with intervening microvilli. $\times 22$ 200. (b) Well formed desmosomes between closely apposed wavy cell membranes. $\times 33700$. (c) Two apposed cell membranes united by a single poorly formed desmosome (arrow). A few amorphous dense bodies are present in cytoplasm. $\times 25600$. (d) Intercellular acinus lined by microvilli. $\times 17300$. 


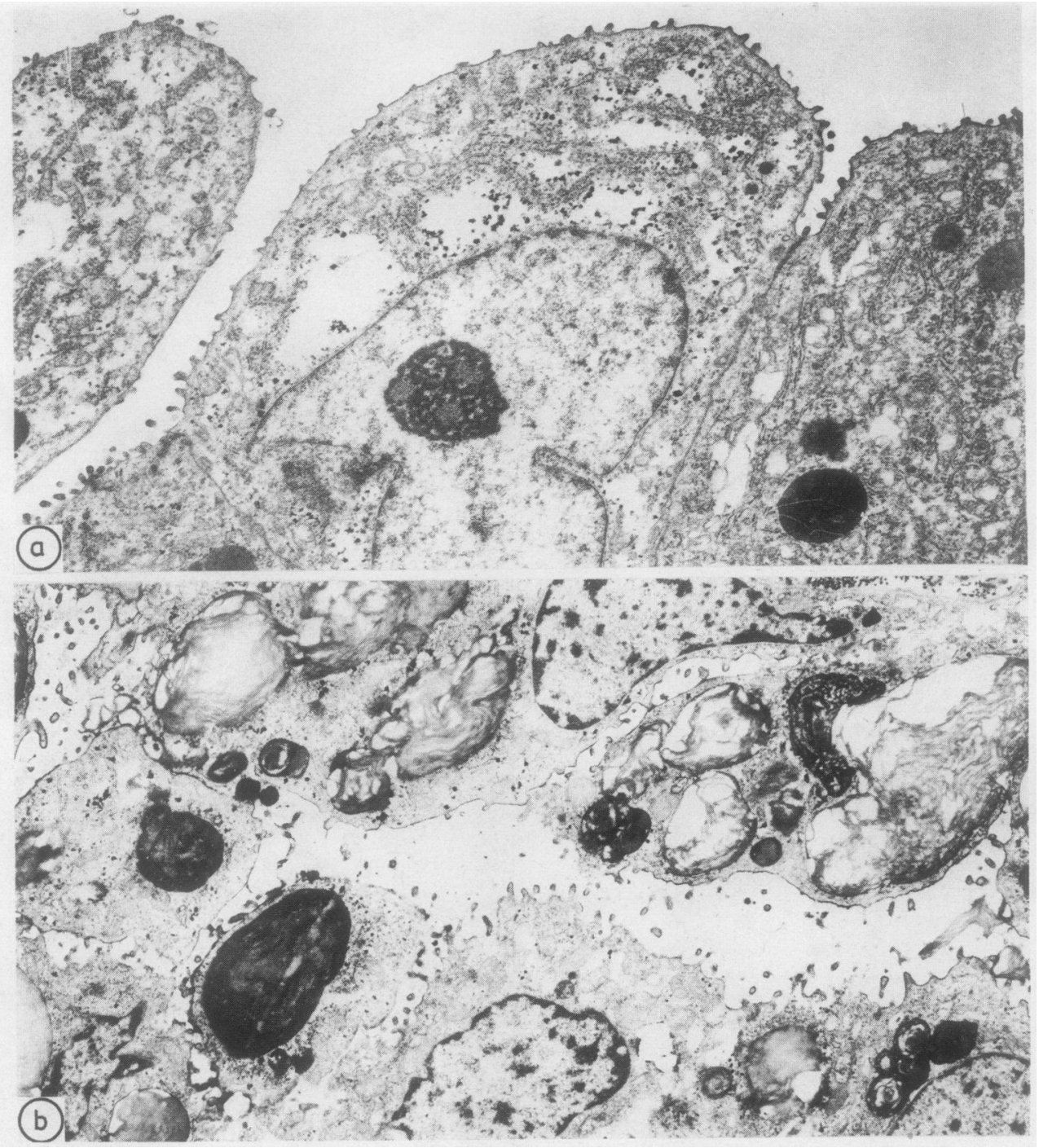

Fig. 4 (a) Tumour cells with surface microvilli lining pseudoacinus similar to that shown in Fig. $1 a$. $\times 6500$. (b) Acinar inclusion, similar to that shown in Fig. le, lined by degenerate type II cells that contain abnormal lamellated intracytoplasmic bodies. $\times 6500$.

complexes (Fig. 4a). The small acini seen on light microscopy were lined with degenerate irregular type II cells (Fig. 4b) with characteristic whorled lamellar cytoplasmic inclusions. These inclusions were larger that those in normal tissue; their lamellae were indistinct and often fused into a fairly structureless electron dense mass.

The cytoplasm contained normal numbers of mitochondria and variable quantities of rough endoplasmic reticulum and free ribosomes. Bundles of tonofilaments were often present, sometimes associ- ated with desmosomes or lying free in the cytoplasm (Fig. 5a); but many cells with abundant filaments bore few desmosomes. In most of the tumour cells there were vacuoles that were either empty or filled with faintly electron dense, amorphous, or flocculent material. Some appeared to be dilated cisterns of endoplasmic reticulum containing lipid or mucus (Fig. $5 \mathrm{~b})$; others, particularly those in cells near foci of necrosis, were degenerate mitochondria (Fig. 5c). In two cases there were small vesicles beneath the cytoplasmic membrane, some of which contained an elec- 


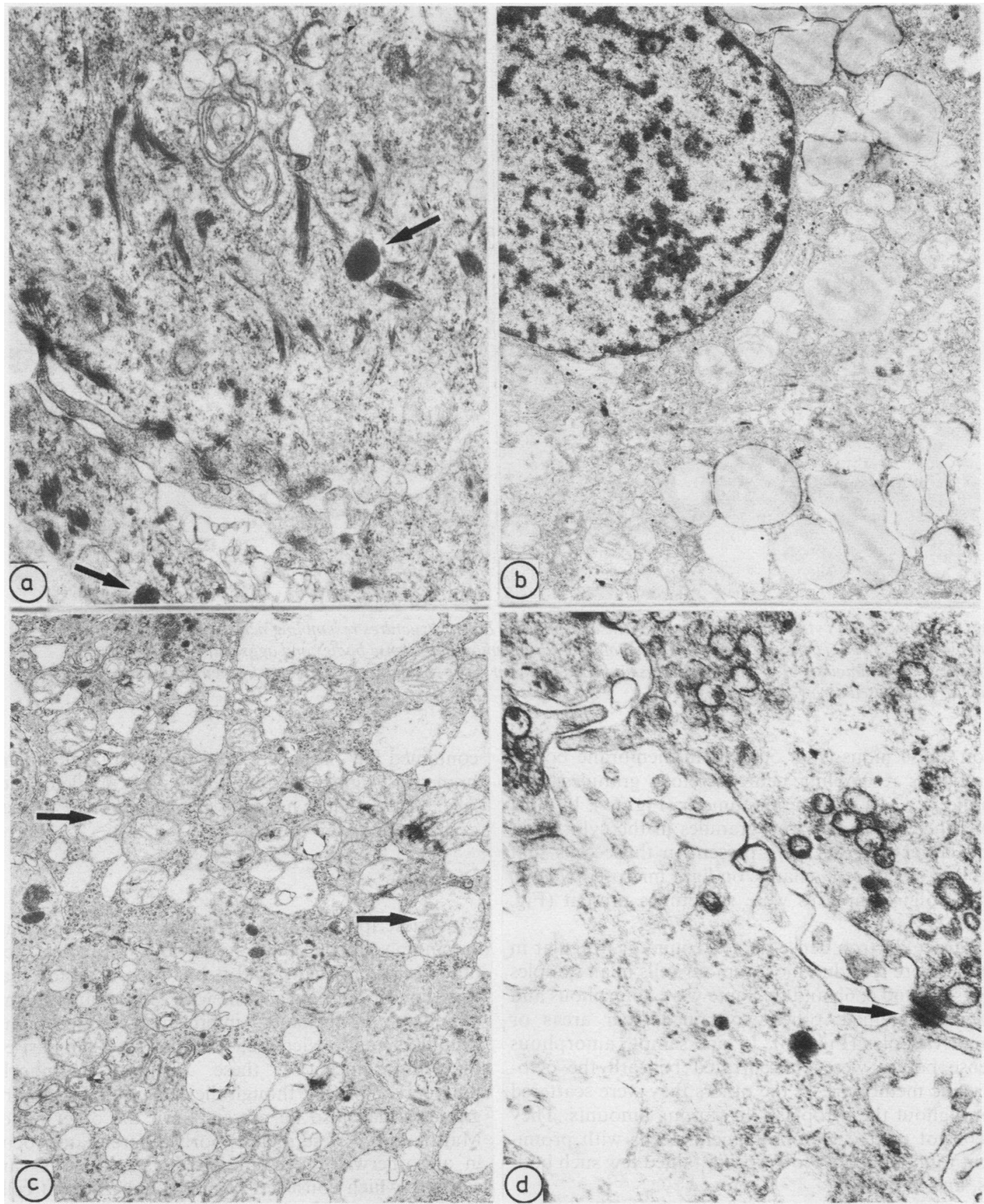

Fig. 5 Tumour cell cytoplasm. (a) Two adjacent tumour cells with irregular cell membranes are joined by desmosomes (bottom left). There are tonofilaments in cytoplasm of one cell (centre), and two dense bodies are present (arrows). $\times 21800$. (b) Cytoplasmic vacuoles containing faintly electron dense material, which could be interpreted as either lipid or dilute mucin. $\times 8700$. (c) Cytoplasmic vacuoles, most of which are dilated endoplasmic reticulum.

Mitochondria are swollen, and two are undergoing vacuolation (arrows) $\times 11000$. (d) Three adjacent cells with desmosome uniting two of them (arrow). Beneath cell membranes at top left and right are small vesicles, some containing ill defined electron dense materia. $\times 25000$. 

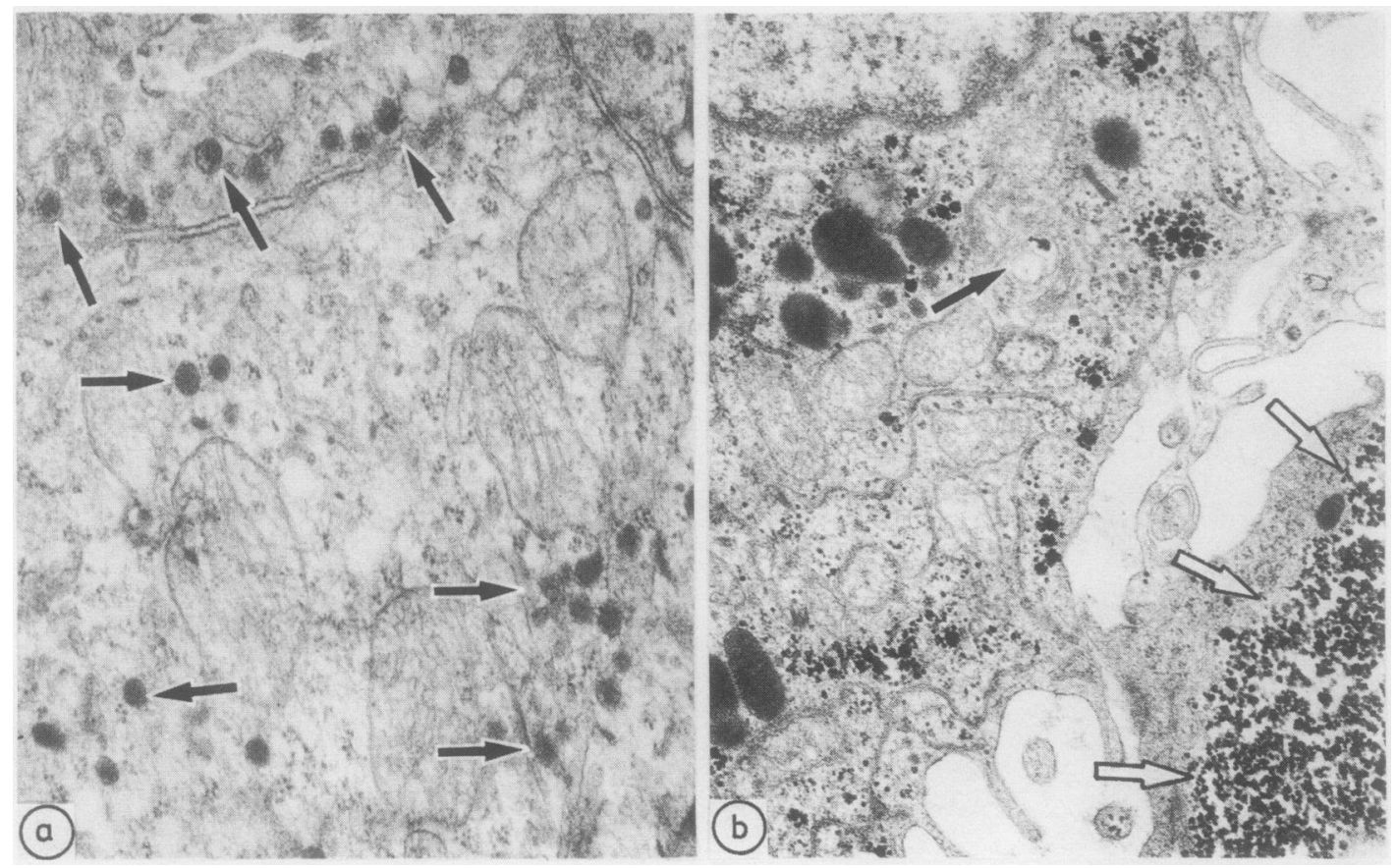

Fig. 6 Tumour cell cytoplasm. (a) Electron dense, membrane bound structures resembling neurosecretory granules (arrows) $\times 25300$. (b) Cell in centre of field contains large, amorphous dense bodies and aggregates of glycogen granules. Large amounts of glycogen are present in cell on lower right (open arrows). Poorly formed Golgi apparatus is indicated by closed arrow. $\times 11700$.

tron dense nidus (Fig. 5d). Small membrane bound structures resembling neurosecretory granules were found in a few cells in one tumour (Fig. 6a). In most cells there were glycogen granules in the cytoplasm, and larger deposits were present in those cells that showed "clear cell" change on light microscopy (Fig. 6b). Golgi complexes were sometimes present (Fig. 6b).

Larger electron dense bodies, round or irregular in shape, were found in most tumour cells in all samples (Figs. 3a and c, 6b and c). Some were amorphous and intensely stained; others contained clear areas or small vacuoles (Fig. 6b). In one sample amorphous dense bodies were concentrated beneath the cytoplasmic membrane; in the others they were scattered throughout the cytoplasm in varying amounts. They were not related to tonofilaments; cells with prominent tonofilaments probably contained few such bodies, and vice versa.

Nuclei were elongated, round, or irregular, generally with a patchy chromatin pattern. Occasionally there was a large single nucleolus and sometimes the nuclear membrane was cleaved (Figs. $2 a$ and $b$ ). Tumour giant cells contained irregular lobulated nuclei with up to three prominent nucleoli; their cytoplasm contained few organelles; and the cytoplasmic membrane was slightly irregular and closely applied to adjacent cells of more normal size. A few poorly formed desmosomes were present.

\section{Discussion}

Most descriptions of the ultrastructure of squamous carcinoma of the lung have dealt with the well differentiated variant, and it has been accepted that this tumour consists of cells with few organelles and abundant desmosomes, intercellular bridges, and tonofilaments. ${ }^{11}$ Nicolescu and Eskenasy emphasised the importance of these features in poorly o differentiated areas, though they stated that secretory $N$ granules may also be present. ${ }^{9}$ On the other hand, N Matthews et al described a poorly differentiated focus in an otherwise well differentiated squamous carcinoma, which consisted of polygonal coherent cells lacking junctions and tonofilaments. ${ }^{8}$ In the cytoplasm there were vesicular structures that seemed to 0 be derived from degenerate mitochondria together with a few dense lysosomal bodies. Three of the 13 cases of peripheral lung cancer described by Mollo's group were classified as squamous on light micros- 
copy. ${ }^{6}$ Although the degree of differentiation was not specified, keratinisation seems to have been minimal, and one tumour showed some evidence of mucus secretion. At an ultrastructural level tonofilaments and desmosomes were described as prominent. In one case there were secretory vesicles filled with amorphous translucent material.

The only comprehensive study of pulmonary squamous carcinoma was by Dingemans and Mooi. ${ }^{11}$ They investigated 40 cases of pulmonary squamous carcinoma, 12 of which were classified as poorly differentiated, though in all there was intercellular bridging and keratinisation. None showed any evidence of adenodifferentiation on light microscopy. In well differentiated areas the overall picture was dominated by tonofilaments and desmosomes, but sometimes either tonofilaments or desmosomes were poorly developed. In poorly differentiated areas these features were inconspicuous. In compact fields there were often well developed desmosomes with no trace of intercellular bridging, and the authors concluded that such cells should be regarded as well differentiated. Giant cells with lobulated nuclei, few organelles, and poorly developed cell junctions were also seen. Like us, they found three distinct types of acinar structure: alveolar inclusions lined with type II cells similar to those described by AlvarezFernandez ${ }^{13}$; small intercellular lumens lined with microvilli; and large lumens containing cell debris, lined with cells bearing microvilli and linked together by junctional complexes.

Intercellular lumens, junctional complexes, and microvilli together with abundant endoplasmic reticulum, intracellular lumens, and secretory vacuoles are characteristic of adenocarcinoma. ${ }^{1114}$ Attention was first drawn to the presence of adenodifferentiation in squamous carcinoma by McDowell et al, ${ }^{14}$ and it is not confined to poorly differentiated tumours, being present in roughly half of all samples overall. ${ }^{11} 14$ Some degree of adenodifferentiation was seen in all our tumours. This feature may be due to the origin of bronchial carcinomas from columnar mucous secreting cells that are able to undergo metaplasia, hyperplasia, and neoplastic change. Interestingly, Hamperl and Hellweg were unable to show mucous secretion in squamous carcinomas of the skin, lip, tongue, and vagina where the normal epithelium does not secrete mucus. ${ }^{15}$ Mucous secretion was found, however, in squamous carcinoma of the cervix, anus, and bladder,

The nature of the various cytoplasmic dense bodies is uncertain. Some were clearly lysosomes, but others were intensely electron dense and amorphous, resembling the polypoid granules and mitochondrial densities described by Heard and Dewar in a well differentiated squamous carcinoma. ${ }^{16}$ In this case the granules projected from the surfaces of keratinised tumour cells, and the mitochondrial densities were associated with the outer layer of the mitochondrial membrane. Heard and Dewar considered that the granules may have been concerned with ectopic production of hormones. In our tumours granules did not project from the cell surfaces nor were they associated with keratinisation, but in one tumour they were aggregated beneath the cytoplasmic membrane. Similar structures have been found in peripheral adenocarcinomas and were interpreted as Clara cell granules. ${ }^{17}$ The smaller electron dense bodies lying in vesicles resemble the neurosecretory granules of small cell carcinoma, but their exact nature is not clear. Several workers"118-20 have described "neurosecretory" bodies in tumours with unequivocal squamous or adenocarcinomatous differentiation.

Eight of our tumours did not fulfil the WHO criteria for squamous carcinom as there was no keratinisation or bridging. Cell typing of such tumours is difficult and highly subjective, and in other centres they would have been classified as large cell or even small cell anaplastic carcinomas. The morphology of all our tumours on light and electron microscopy was similar, however, whether keratinisation or bridges were present or not. In addition, as Churg et al showed, ${ }^{18}$ apparent small cell anaplastic carcinomas of fusiform or polygonal cell type may have the ultrastructural features of squamous carcinoma and be associated with a better prognosis than true oat cell carcinoma.

We conclude that there is a group of poorly differentiated bronchial neoplasms that are squamoid in appearance and they should be included in the category of poorly differentiated squamous carcinoma. The presence or absence of minor degrees of keratinisation or bridging is of less diagnostic importance than the morphology of individual cells and overall pattern. At an ultrastructural level such tumours characteristically show the features of both adenocarcinoma and squamous carcinoma.

This work was supported by a grant from the West Midlands Regional Health Authority. We thank Mrs Ruth Fry for secretarial help.

\section{References}

${ }^{1}$ Hattori S, Matsuda M, Tateishi R, Terazawa T. Electron microscopic studies on human lung cancer cells. Gann 1967;58:283-90.

${ }^{2}$ Obiditsh-Mayer L, Breitenfellner G. Electron microscopy in cancer of the lung. Cancer 1968;21:945-51.

${ }^{3}$ Coalson JJ, Mohr JA, Pirtle JK, Dee AL, Rhoades ER. Electron microscopy of neoplasms in the lung with special emphasis on the alveolar cell carcinoma. Am Rev Respir Dis 1970;101:181-97.

${ }^{4}$ Razzuk MA, Race GJ, Lynn JA, Martin JA, Urschel HC, Paulson DL. Observations on ultrastructural morphology of bronchogenic carcinoma. J Thorac Cardiovasc Surg 1970;59:581-7. 
${ }^{5}$ Lupulescu A, Boyd CB. Lung cancer: a transmission and scanning electron microscopic study. Cancer 1972;29:1530-8.

${ }^{6}$ Mollo F, Canese MG, Campobasso O. Human peripheral lung tumours: light and electron microscopic correlation. $\mathrm{Br} J$ Cancer 1973;27:173-82.

${ }^{7}$ Shimasato Y, Melamed MR, Nettesheim P, eds. Morphogenesis of lung cancer. Boca Raton: CRC Press, 1982.

${ }^{8}$ Matthews MJ, Mackay B, Lukeman J. Pathology of non-small cell carcinoma of the lung. Semin Oncol 1983;10:34-55.

${ }^{9}$ Nicolescu PG, Eskenasy A. Electronmicroscopic observations on epidermoid (squamous cell) carcinoma of the lung. Morphologie et Embryologie (Bucuresti) 1984;301:31-5.

${ }^{10} \mathrm{Green}$ GJ, Brown AJ, Diverti MB. Fine structure of squamous cell carcinoma of the lung. Mayo Clin Proc 1969;44:85-95.

${ }^{11}$ Dingemans KP, Mooi WJ. Ultrastructure of squamous cell carcinoma of the lung. Pathol Ann 1984;173:249-73.

12 World Health Organisation. Histological typing of lung tumours. 2nd ed. Geneva: World Health Organisation, 1981.

${ }^{13}$ Alvarez-Fernandez E. Alveolar trapping in pulmonary carcinomas. Diagn Histopathol 1982;5:59-64.

${ }^{14}$ McDowell EM, McLaughlin JS, Merenyi DK, Kieffer RF, Harris CC, Trump BF. The respiratory epithelium. V. Histogenesis of lung carcinomas in the human. Journal of the National Cancer Institute 1978;61:587-99.

${ }^{15}$ Hamperl H, Hellweg G. On mucoepidermoid tumours of different sites. Cancer 1957;10:1187-92.

${ }^{16}$ Heard BE, Dewar A. Squamous cell carcinoma of bronchus: polypoid granules and mitochondrial densities found by electron microscopy. Diagn Histopathol 1982;5:189-95.

${ }^{17}$ Ogata T, Endo K. Clara cell granules of peripheral lung cancers. Cancer 1984;54:1635-44.

${ }^{18}$ Churg A, Johnston WH, Stulbarg M. Small cell squamous and mixed small cell squamous-small cell anaplastic carcinomas of the lung. Am J Surg Pathol 1980;4:225-63.

${ }^{19}$ McDowell EM, Trump BF. Pulmonary small cell carcinoma showing tripartate differentiation in individual cells. Hum Pathol 1981;12:286-94.

${ }^{20}$ McDowell EM, Wilson TS, Trump BF. Atypical endocrine tumours of the lung. Arch Pathol Lab Med 1981;105:20-8.

Requests for reprints to: Dr CW Edwards, Department of Histopathology, East Birmingham Hospital, Bordesley i Green East, Birmingham B9 5ST, England. 